Revista de Ciências Agrárias

\title{
Índice mitótico e viabilidade celular de calos embriogênicos de murici-pequeno
}

AUTORES:

Raírys Cravo Herrera ${ }^{1}$

Renato Paiva ${ }^{2}$

Vanessa Cristina Stein ${ }^{3}$

Caio Césio Salgado 4

Marcelo Murad Magalhães ${ }^{5}$

Fernanda Pereira Soares ${ }^{6}$

1 Universidade Federal do Pará, 68.372-040. Altamira, PA, Brasil.

2 Universidade Federal de Lavras, 37.200-000. Lavras, MG, Brasil.

${ }^{3}$ Universidade Federal de Goiás, 75.801-615. Jataí, GO, Brasil.

${ }^{4}$ Universidade Federal de Viçosa, 36.570-000, Viçosa, MG, Brasil.

${ }^{5}$ Embrapa Amazônia Oriental, Caixa Postal 48, 66.095-100, Belém, PA, Brasil.

${ }^{6}$ Ministério da Agricultura, Pecuária e Abastecimento. 37.200-000, Lavras, MG, Brasil.

Recebido: 26/10/2010

Aprovado: 11/05/2011

AUTOR CORRESPONDENTE:

Raírys Cravo Herrera

E-mail:rairys@gmail.com

PALAVRAS-CHAVE:

Embriogênese somática

Planta medicinal,

2,4-D, Cerrado

Byrsonima intermedia,

divisão celular

KEY WORDS:

Somatic embryogenesis

Medicinal plant

2,4-D, Cerrado

Byrsonima intermedia

cell division

\section{The Mitosis index and cell viability in embryonic calli of murici-pequeno}

Resumo: Byrsonima intermedia é uma espécie lenhosa e medicinal de ocorrência nos Cerrados brasileiros. O objetivo desta pesquisa foi determinar o padrão de divisão e viabilidade de células com características embriogênicas. Segmentos foliares foram inoculados em meio de cultura MS suplementada com 1,0 mg L-1 de 2,4-D. As repicagens foram efetuadas por três vezes, todas aos sessenta dias, resultando em três subcultivos. Avaliou-se a viabilidade celular e o índice mitótico de células com características embriogênicas, no segundo subcultivo. No segundo subcultivo, aos 20 e 40 dias, ocorrem os maiores índices de divisão celular. Até os 80 dias de incubação dos calos, ocorre a maior porcentagem de células viáveis com características embriogênicas.

ABSTRACT: Byrsonima intermedia is a woody medicinal plant commonly found in the Brazilian Cerrado region. The aim of this study was to determine the cell division pattern and viability of cells with embryogenic characteristics. Leaf segments were inoculated in MS medium supplemented with $1.0 \mathrm{mg} \mathrm{L}-1$ 2,4-D. Three subcultures were carried out over sixty days. The viability and mitosis index was calculated for cells with embryogenic capacity from the second subculture. The highest cell division index was found in the second subculture, after 20 and 40 days. The highest percentage of viable cells with embryogenic properties was found in the first 80 days. 


\section{Introdução}

O murici-pequeno (Byrsonima intermedia A. Juss.), pertencente à familia Malpighiaceae, é um arbusto nativo do Cerrado que apresenta, na casca do caule, atividade medicinal adstringente nas diarreias e disenterias (RODRIGUES; CARVALHO, 2001). Lorenzi (2002) menciona que o gênero Byrsonima apresenta taxa de germinação baixa e emergência lenta da plântula, dificultando a sua propagação sexuada.

A micropropagação é uma das principais aplicações da cultura de tecidos, especialmente para as plantas de difícil propagação pelos métodos convencionais. A cultura de tecidos também é de grande interesse para as espécies que se encontram em vias de extinção, em função, principalmente, da intervenção do homem em seu habitat. Com essa tecnologia, é possível conservar essas espécies in vitro, em meios de manutenção, e programar a produção comercial (CERQUEIRA, 1999).

Os protocolos baseados na cultura de segmentos nodais, gemas apicais e axilares, utilizados na organogênese, geralmente, mostram baixa eficiência em termos regenerativos potenciais. Nesse tipo de cultura de segmentos nodais, gemas apicais e axilares, a sobrevivência das plantas no final da fase ex vitro é frequentemente baixa, o que reduz a produção potencial da micropropagação via organogênese. Em paralelo, esforços têm sido direcionados para a indução e o controle da embriogênese somática (GUERRA et al., 1999).

Apesar das vantagens deste tipo de cultivo em relação à organogênese, a conversão de embriões somáticos em plantas ainda é uma etapa que pode apresentar dificuldades e, dessa forma, estudos complementares, para a caracterização morfológica, citológica e bioquímica, podem elucidar as possíveis causas relacionadas a este processo. Para o muricipequeno, estes dados ainda são desconhecidos.

O objetivo desta pesquisa foi caracterizar as células envolvidas no processo de regeneração via embriogênese somática, a fim de fornecer subsídios para a otimização de protocolos de propagação in vitro de murici-pequeno.

\section{Material e Métodos}

Para a obtenção de explantes, sementes de murici-pequeno foram germinadas in vitro em meio de cultura WPM 50\% sem sacarose, como descrito por Nogueira et al. (2004). Destas plântulas foram obtidos segmentos foliares de $0,25 \mathrm{~cm}^{2}$, os quais, posteriormente, foram inoculados em tubos de ensaio contendo $10 \mathrm{~mL}$ do meio de cultura MS (MURASHIGE; SKOOG, 1962), suplementado com 1,0 mg L-1 de ácido 2,4-diclorofenoxiacético (2,4-D) e $3 \%$ de sacarose, segundo Nogueira et al. (2007). As culturas foram incubadas no escuro, a $27 \pm 2{ }^{\circ} \mathrm{C}$ e umidade relativa de $70 \%$.

Após sessenta dias, os calos foram repicados segundo a curva de crescimento determinada por Nogueira et al. (2008). As repicagens foram efetuadas por três vezes, todas aos sessenta dias, resultando em três subcultivos. Avaliou-se a porcentagem de ocorrência de estruturas globulares em calos provenientes do cultivo inicial e dos três subcultivos seguintes.

Investigou-se o padrão de índice mitótico e viabilidade celular de calos no segundo subcultivo, a fim de confirmar se a época de repicagem dos calos foi ideal para a maior formação de embriões globulares no terceiro subcultivo.

Para a verificação do índice mitótico, duas amostras de calos, de aproximadamente 0,5 g cada, obtidas a partir do segundo subcultivo, em meio nutritivo MS suplementado com 1,0 $\mathrm{mg} \mathrm{L}^{-1}$ de 2,4-D, foram coletadas aos 10, 20, 40, 60, 80, 100 e 120 dias da curva de crescimento e armazenadas em fixador Carnoy (3 partes de etanol:1 parte de ácido acético), por 20 horas, em temperatura ambiente. Após esse período, as amostras foram mantidas a $-22{ }^{\circ} \mathrm{C}$, para posterior preparação para análise microscópica.

As frações de calos foram transferidas para eppendorf contendo 0,5 mL de solução tampão McIlvaine ( $\mathrm{pH} 7,0)$ e, em seguida, foram filtradas em peneira com malha de $100 \mu \mathrm{m}$ e centrifugadas a $6.000 \mathrm{rpm}$ por 2 segundos. O precipitado foi ressuspendido em tampão McIlvaine e, após a formação do pellet, retirou-se o excesso da solução. Em lâmina, adicionaram-se $10 \mu \mathrm{L}$ de 4,6-Diamidino-2-fenilindol (Dapi) na concentração de $2 \mu \mathrm{g} \mathrm{mL}^{-1}$ a $20 \mu \mathrm{L}$ da suspensão celular final. Após 5 minutos, procedeu-se a observação em microscópio de fluorescência Olympus BX 60, utilizando-se filtro WU sob aumento total de 400X.

$\mathrm{O}$ índice mitótico [(número de células em mitose/número total de células) x 100] foi obtido para 200 células. Os dados foram analisados utilizandose o delineamento inteiramente casualizado, com seis repetições por período de coleta. Utilizou-se regressão polinomial a 5\% de probabilidade.

Para os testes de viabilidade celular, duas amostras de calos, contendo $1 \mathrm{~g}$ de matéria fresca cada, foram obtidas a partir do segundo subcultivo, em intervalos de 10 dias, até o final de 120 dias de cultivo. Cada amostra foi homogeneizada em $10 \mathrm{~mL}$ 
de solução de manitol 0,6 $\mathrm{M} \mathrm{e} \mathrm{CaCl}_{2}$ 0,03 $\mathrm{M}$, por 30 minutos, a $90 \mathrm{rpm}$ e em temperatura de $27 \pm 2{ }^{\circ} \mathrm{C}$. $\mathrm{Na}$ ausência de luz, estas amostras foram filtradas em peneira com malha de $100 \mu \mathrm{m}$, retirando-se 980 $\mu \mathrm{L}$ da suspensão e adicionando-se $20 \mu \mathrm{L}$ de uma solução $0,5 \%$ de FDA (diacetato de fluoresceína) em eppendorf, resultando em 0,01\% de FDA. Após 5 minutos, procedeu-se a contagem de células viáveis com fluorescência verde e formato isodiamétrico, em microscópio de fluorescência Olympus BX 60, utilizando-se o filtro Wiba, sob aumento total de 100X.

Os dados foram analisados utilizando-se o delineamento inteiramente casualizado, com quatro repetições por período de coleta. Utilizou-se regressão polinomial a $5 \%$ de probabilidade.

\section{Resultados e Discussão}

A coloração com Dapi permitiu a visualização dos núcleos em diferentes fases do ciclo celular, como interfase e metafase. Segundo Nkongolo e Klimaszewska (1993), as culturas embriogênicas apresentam um grande número de células em diferentes estágios mitóticos. Steinmacher et al. (2011), utilizando coloração com Dapi, observaram que o local de desenvolvimento do embrião em calos de Bactris gasipaes apresenta células que estão em diferentes estágios de divisão celular.

Os índices mitóticos, entre os 20 e 40 dias do segundo subcultivo, não diferiram estatisticamente entre si, apresentando o máximo de divisão celular observado na curva (17 e 18,16\%, respectivamente). Já a partir dos 60 dias houve redução no índice mitótico, caindo para $6 \%$ aos 80 dias e $2 \%$ aos 120 dias de cultivo (Figura 1).

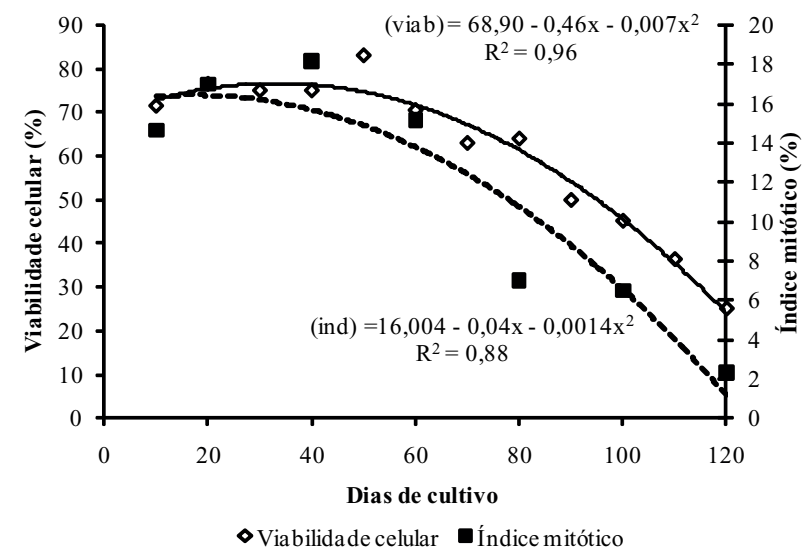

Figura 1. Viabilidade celular e Índice mitótico de calos subcultivados em meio MS suplementado com 1,0 $\mathrm{mg} \mathrm{L}^{-1}$ de 2,4-D, durante 120 dias de permanência no escuro. Nível de significância de $5 \%$.
Os dados verificados com relação ao índice mitótico corroboram com a curva de crescimento do murici-pequeno, que segue um padrão do tipo sigmoide, com seis fases distintas: lag, exponencial, linear, desaceleração, estacionária e de declínio. A fase lag ocorre até o $20^{\circ}$ dia após a inoculação, apresentando $95 \%$ de crescimento. A segunda fase, a exponencial, estendeu-se do $20^{\circ}$ ao $40^{\circ}$ dia de cultivo, com $88 \%$ de crescimento. A fase linear, com $51 \%$ de crescimento, foi observada entre o $40^{\circ}$ e o $60^{\circ}$ dia de cultivo. Entre o $60^{\circ}$ e o $80^{\circ}$ dia após a inoculação ocorreu a fase de desaceleração, apresentando 22\% de crescimento (NOGUEIRA et al., 2008).

Portanto, os maiores valores de índice mitótico observados neste trabalho estão compreendidos na fase exponencial da curva de crescimento de calos de murici-pequeno. Segundo Santos et al. (2003) e Serra et al. (2000), esta fase é caracterizada pela rápida divisão celular, o que pode explicar a maior porcentagem de índice mitótico verificada. Além disso, a queda no índice mitótico aos 80 dias após inoculação refere-se à fase de desaceleração da curva de crescimento.

Hao et al. (2002) detectaram um índice mitótico de $40 \%$ em suspensão celular de citrus (Citrus sinensis Osbeck) aos seis dias após a inoculação em meio de cultura. Já Winicur et al. (1998), investigando a ação do 2,4-D na divisão celular de suspensão de tabaco (Nicotiana tabacum), obtiveram aproximadamente $7 \%$ de índice mitótico no quinto dia de cultivo. Em protoplastos de Solanum lycopersicoides aos sessenta dias de cultivo e em protoplastos de Helianthus maximiliani aos 4 dias de cultivo, o índice alcançou 10 e $17 \%$, respectivamente (TYLICKI et al., 2002; BINSFELD et al., 2000).

Segundo Pasternak et al. (2002), as células que são capazes de produzir embriões somáticos são mitoticamente ativas. Steinmacher et al.(2011) relatam que os eventos mitóticos mais numerosos são observados na camada de células do setor embriogênico do calo, que também apresentam núcleo central com um ou dois nucléolos.

Nas pesquisas de Steiner et al. (2005) e Stein et al. (2010), as células embriogênicas, de maneira geral, apresentam características comuns ao comportamento de células meristemáticas ativas, incluindo células isodiamétricas, rápida divisão mitótica, pequeno tamanho, citoplasma denso, núcleo grande com nucléolo proeminente.

Winicur et al. (1998) ressaltam que a conformação isodiamétrica observada em células de calos embriogênicos corresponde diretamente ao aumen- 
to do índice de divisão celular. Esses autores também observaram que a privação de auxina no meio de cultura é limitante para a divisão celular, levando à redução no índice mitótico e induzindo o alongamento das células. Diante disso, a redução do índice mitótico aos 80 e 120 dias pode ser devida à redução de auxinas no meio de cultura, sendo necessária a realização de subcultivos mais frequentes.

Quanto à viabilidade celular, os valores encontrados entre os 10 e 80 dias não diferiram estatisticamente entre si. Entretanto, a maior porcentagem de células isodiamétricas com fluorescência verde ocorreu aos 50 dias, $83 \%$ (Figura 1). A partir dos 90 dias, o número de células com características meristemáticas declinou consideravelmente até o último dia de incubação (120 dias), atingindo menos de 30\%. De acordo com Filonova et al. (2000) e Fehér et al. (2003), as células isodiamétricas pequenas e de citoplasma denso são as que apresentam maior potencial embriogênico.

Considerando que os valores de índice mitótico não apresentaram diferenças significativas entre os 20 e 50 dias, a análise da viabilidade celular definiu que a melhor época para a transferência do segundo para o terceiro subcultivo de células, de modo a possibilitar a embriogênese somática, é até os 80 dias.

As análises de índice mitótico e viabilidade celular permitiram a determinação do período de melhor transferência de células com alta capacidade embriogênica. Os resultados obtidos concordam com as observações de Guerra et al. (1999), que comentam que o ponto mediano da fase linear da curva de crescimento da cultura seria o período ideal de transferência das células para meio líquido, a fim de otimizar a biomassa para a produção de embriões somáticos.

A utilização de FDA foi sugerida por Wildhom (1972), em calos de tabaco e, desde então, tem sido reportada por diversos autores (FILONOVA et al., 2000; CLARKE et al., 2001; FEHÉR et al., 2003; IAKIMOVA et al., 2005). Trabalhos passaram a certificar a viabilidade celular com este corante, como o de Steward et al. (1999), com alfafa (Medicago sativa L.), cuja suspensão apresentou $80 \%$ de viabilidade nos primeiros dias de cultivo. Te-chato et al. (2005) detectaram uma viabilidade de protoplastos de dendezeiro (Elaeis guineensis) de, aproximadamente, $82 \%$.

Deste modo, os resultados do índice mitótico demonstraram que a época ideal para a transferência de células com potencial embriogênico, sem a perda de viabilidade celular, não deve ultrapassar os 50 dias, pois seria o ponto mediano da fase line- ar da curva de crescimento, como determinado por Nogueira et al. (2008).

\section{Conclusões}

Os maiores índices de divisão celular em calos de murici-pequeno ocorrem aos 20 e 40 dias do segundo subcultivo.

Até os 80 dias de incubação dos calos ocorre a maior porcentagem de células viáveis com características embriogênicas.

\section{Agradecimentos}

À Fundação de Amparo à Pesquisa do Estado de Minas Gerais (Fapemig) e ao Conselho Nacional de Desenvolvimento Científico e Tecnológico (CNPq).

\section{Referências}

BINSFELD, P.C.; PETERS, J.A.; SCHNABL, H. Efeito de herbicidas sobre a polimerização dos microtúbulos e indução de micronúcleos em protoplastos de Helianthus maximiliani. Revista Brasileira de Fisiologia Vegetal, v.12, n.3, p. 263-272, 2000.

CERQUEIRA, E.S. Propagação e calogênese in vitro em erva-de-touro (Tridax procumbens L.), uma planta medicinal. 1999. 81f. Tese (Mestrado em Fisiologia Vegetal). Lavras, 1999.

CLARKE, J.M.; GILLINGS, M.R.; ALTAVILLA, N.; BEATTIE, A.J. Potencial problems with fluorescein diacetate assays of cell viability when testing natural products for antimicrobial activity. Journal of Microbiological Methods, Amsterdam, v.46, n.3, p.261-267, 2001.

FEHÉR, A.; PASTERNAK, T.P.; DUDITS, D. Transition of somatic plant cells to an embryogenic state. Plant Cell, Tissue and Organ Culture, Dordrecht, v.74, n.3, p.201-228, 2003.

FILONOVA, L.H.; BOZHKOV, P.V.; BRUKHIN, V.B.; DANIEL, G.; ZHIVOTOVSKY, B.; ARNOLD, S. von. Two waves of programmed cell death occur during formation and development of somatic embryos in the gymnosperm, Norway spruce. Journal of Cell Science, London, v.113, n.24, p.4399-4411, 2000.

GUERRA, P.G.; TORRES, A.C.; TEIXEIRA, J.B. Embriogênese somática e sementes sintéticas. In: TORRES, A.C.; CALDAS, L.S.; BUSO, I.A. (Eds.). Cultura de tecidos e transformação genética de plantas. Brasilia: Embrapa, 1999. v.2, p.533-568. 
HAO, Y.J.; YOU, C.X.; DENG, X.X. Cell size as a morphological marker to calculate the mitotic index and ploidy level of citrus callus. Plant Cell Report, New York, v.20, n.3, p.1123-1127, Oct. 2002.

IAKIMOVA, E.; KAPCHINA-TOTEVA, V.; JONG, A.; ATANASSOV, A.; WOLTERING, E. Involvement of ethylene, oxidative stress and lipid-derived signals in cadmium-induced programmed cell death in tomato suspension cells. BMC Plant Biology, Yalta, v.5, n.1, p.1-5, 2005.

LORENZI, H. Árvores brasileiras: manual de identificação e cultivo de plantas arbóreas nativas do Brasil. São Paulo: Nova Odessa, 2002. v.1, 386 p.

MURASHIGE, T.; SKOOG, F. A revised medium for rapid growth and bioassays with tobacco tissue cultures. Physiologia Plantarum, Copenhagen, v.15, n.3, p.473-497, Mar. 1962.

NKONGOLO, K.K.; KLIMASZEWSKA, K. Karyotype analysis and optimization of mitotic index in Picea mariana (black spruce) preparations from seedling root tips and embryogenic cultures. Heredity, v.73, p.11-17, 1994.

NOGUEIRA, R.C.; PAIVA, R.; CASTRO, A.H. de; VIEIRA, C.V.; ABBADE, L.C.; ALVARENGA, A.A. Germinação in vitro de murici-pequeno (Byrsonima intermedia A. Juss.). Ciência e Agrotecnologia, v.28, n.5, p.1053-1059, 2004.

NOGUEIRA, R.C.; PAIVA, R.; OLIVEIRA, L. M. de; SOARES, G. de A.; SOARES, F. P.; CASTRO, A.H.F.; PAIVA, P.D. de O. Indução de calos em explantes foliares de murici-pequeno (Byrsonima intermedia A. Juss.). Ciência e Agrotecnologia, v.31, n.2, p.366-370, 2007.

NOGUEIRA, R.C.; PAIVA, R.; LIMA, E.C.; SOARES, G.A.; OLIVEIRA, L.M.; SANTOS, B.R.; EMRICH, E.B.; CASTRO, A.H.F. Curva de crescimento e análises bioquímicas de calos de muricipequeno (Byrsonima intermedia A. Juss.). Revista Brasileira de Plantas Medicinais, v.10, n.1, p.4448, 2008.

PASTERNAK ,T.P.; PRINSEN, E.; AYAYDIN, F. The role of Auxin, $\mathrm{pH}$, and stress in the activation of embryogenic cell division in leaf protoplastderived cells of alfalfa. Plant Physiology, v.129, p.18071819, 2002.

RODRIGUES, V.E.G.; CARVALHO, D.A. de. Plantas medicinais no domínio dos cerrados. Lavras: Ufla, 2001. 180p.
SANTOS, C.G.; PAIVA, R.; PAIVA, P.D.O.; PAIVA, R. Indução e análise bioquímica de calos obtidos de segmentos foliares de Coffea arabica L., cultivar rubi. Ciência e Agrotecnologia, Lavras, v.27, n.3, p.571-577, 2003.

SERRA, A.G.P.; PAIVA, R.; PAIVA, P.D.O. Análises bioquímicas de calos formados de explantes foliares de castanha-do-brasil (Bertholletia excelsa H. B. K.). Ciência e Agrotecnologia, Lavras, v.24, n.4, p.833-840, 2000.

STEIN, V.C.; PAIVA, R.; VARGAS, D.P.; SOARES, P.S.; ALVES, E.; NOGUEIRA, G.F. Ultrastructural calli analysis of Inga vera Willd. subsp. Affinis (DC.) T.D. Penn. Revista Árvore, Viçosa, v.34, n.5, Oct. 2010 .

STEINER, N.; VIEIRA, F. do N.; MALDONADO, S.; GUERRA, M.P. Effect of Carbon source on morphology and histodiffentiation of Araucaria angustifolia embryogenic cultures. Brazilian Archives of Biology and Technology, v.48, n.6, p.895-903, Nov. 2005.

STEINMACHER, D.A.; GUERRA, M.P.; SAARESURMINSKI, K.;LIEBEREI, R.A. Temporary immersion system improves in vitro regeneration of peach palm through secondary somatic embryogenesis. Annals of Botany. Disponivel em: www.aob.oxfordjournals.org. Acesso em: 2011.

STEWARD, N.; MARTIN, R.; ENGASSER, J.M.; GOERGEN, J.L. A new methodology for plant cell viability assessment using intracellular esterase activity. Plant Cell Reports, v.19, n.2, p.171 - 176, 1999.

TE-CHATO, S.; HILAE, A.; MOOSIKAPALA, L. Microcolony formation from embryogenic callusderived protoplasts of oil palm. Songklanakarin Journal Science Technology, v.27, n.4, p.685-691, 2005.

TYLICKI, A.; BURZA, W.; MALEPSZY, S. Structural and ultrastructural analysis of Solanum lycopersicoides protoplasts during diploid plant regeneration. Annals of Botany, v.90, p.269-278, 2002.

WIDHOLM, J.M. The use of fluorescein diacetate and phenosafranine for determining viability of cultured plant cells. Stain Technology, Baltimore, v.47, n.4, p. 189-194, 1972.

WINICUR, Z.M., ZHANG, G.F., STAEHELIN, L.A. Auxin deprivation induces synchronous Golgi differentiation in suspension-cultured tobacco BY-2 cells. Plant Physiology, v.117, p.501-513, 1998. 